Research Article

\title{
Geological Analysis and Model Test of Bedding Rock Cutting Landslide
}

\author{
Tian-Wen Lai, ${ }^{1}$ Zhi-Yang Ji, ${ }^{1,2}$ Hong-Gang Wu ${ }^{D},{ }^{2}$ Shao-Long Zhang, ${ }^{1,2}$ Hao Lei $\left(\mathbb{D},{ }^{1}\right.$ \\ and Yu Liang ${ }^{1}$ \\ ${ }^{1}$ College of Civil Engineering, Lanzhou Jiaotong University, Lanzhou 730000, Gansu, China \\ ${ }^{2}$ Northwest Research Institute Co., Ltd. of CREC, Lanzhou 730000, Gansu, China \\ Correspondence should be addressed to Hong-Gang Wu; 271462550@qq.com
}

Received 22 March 2021; Accepted 4 May 2021; Published 27 May 2021

Academic Editor: Timo Saksala

Copyright ( 2021 Tian-Wen Lai et al. This is an open access article distributed under the Creative Commons Attribution License, which permits unrestricted use, distribution, and reproduction in any medium, provided the original work is properly cited.

To explore the staged catastrophic evolution mechanism and failure process of bedding rock landslides under construction disturbance and rainfall conditions, we selected water content, displacement, strain, and soil stress as the study objects and carried out a model test. Combining the test phenomena, the following conclusions are drawn: first, bedding rock landslides have experienced three different stages of initial, constant velocity, and accelerated deformation affected by construction and rainfall factors. Then, the mode of bedding rock landslides is both sliding and traction sliding compound sliding mode. Finally, in the initial and constant deformation stages, the stress and strain values in the soil both increase slightly. In the accelerated deformation stage, the horizontal and vertical deformation at the slope foot increases sharply. Meanwhile, the strain value increases greatly, the stress decreases, and the stress in the slope increases significantly. Therefore, stress, strain, and displacement can be used as early warning indicators for staged disasters of bedding rock landslides.

\section{Introduction}

Construction excavation and rainfall factors have an important influence on the catastrophic evolution of landslides along bedding rock cutting. Kalinin et al. found that, under the influence of continuous rainfall, the water infiltrating into the fissures will flow along between the bedrock and the slip body [1]. The slip surface continuously penetrated to the foot of the slope, which caused the shear strength of the landslide body to continuously decrease, which in turn affected the stability of the slip body and causes the landslide. Ventisette et al. [2], Lollino et al. [3], and Toshiya et al. [4] explained the mechanism of landslide disaster and deformation failure by establishing physical test models. Xu et al. [5] analyzed a large number of landslide cases and divided the landslide disaster process into two deformation stages: slow sliding and accelerated sliding. Crozier [6] found that rainfall accelerates the sliding of slip body. Rahimi et al. [7] conducted a sensitivity analysis of the hydraulic parameters of the soil under rainfall conditions and then studied its adverse effects on the stability of the landslide. Oh and Vanapalli [8] explained the relationship between soil shear strength and slope stability with the aid of landslide rainfall test. Luciani et al. [9] and Martelloni et al. [10] established a rainfall threshold model and found that when the rainfall was greater than the landslide instability critical value, then the model unit maybe loses stability and slip. Xia et al. [11] analyzed geological data and carried out drilling sampling work, they found that, under the influence of rainfall, the stress of the weak interlayer in the landslide body gradually decreased, and the slip surface gradually penetrated, accelerating the occurrence of landslide diseases. Ma and Zhang [12] conducted geological surveys and found that, under the influence of rainfall, the soft interlayer of the bedding landslide softened in contact with water, which is the internal cause of the sliding of the bedding landslide. Mao et al. [13] conducted surveys of geological data, combined the results of numerical simulations, and found that the weak interlayer has a controlling effect on the sliding of the landslide body. The sliding process starts from the 
front edge of the slip body and pulls the rock mass on the back edge to slip. Wasowski [14], Chowdhury and Flentje [15], Sengupta et al. [16], Berti et al. [17], Melillo et al. [18], and Ko and Lo [19] also used the rainfall threshold to study the instability and slip problem of slopes. In addition, Floris and Bozzano [20] improved the traditional rainfall threshold model to predict the probability of landslide occurrence. Vennari et al. [21] summarized and analyzed 251 landslide cases in Italy and used continuous rainfall time thresholds to predict landslides. Park et al. [22] used GIS technology to predict landslide disasters caused by rainfall. Crosta [23] and Dolojan et al. [24] combined rainfall intensity, soil characteristics, and other factors to analyze the possible instability sliding problems of slopes.

Previous studies mainly focused on the damage mechanism of landslide disasters, the division of landslide deformation stages, and the influence of rainfall thresholds on landslide stability. They did not use physical and mechanical indicators such as stress, strain, and displacement to study the staged catastrophic evolution process of landslides and early warning of landslide disasters. In view of this, this paper conducts a model test and analyzes the staged catastrophic evolution process of bedding rock landslides. After analyzing the change trend of stress, strain, and displacement in the soil body, it reveals the deformation and failure mechanism of the landslide body and then plays an early warning role.

\section{Project Overview}

The landslide site selected for this test is located at K17+700 $\sim \mathrm{K} 17+900$ of Taiping, Tianfu International Airport Expressway, Shuangliu district, Chengdu. The front edge of the landslide has a highway cutting structure. Figure 1 is $\mathrm{K} 17+700 \sim \mathrm{K} 17+900$ landslide view.

According to engineering geological survey data [25], the landslide is a bedding rock cutting landslide, and the thickness of the slip body is between $4.1 \mathrm{~m}$ and $15.6 \mathrm{~m}$. The slip body is mainly composed of block stones and mudstone, the slip surface is a soft interlayer of silty mudstone, and the main shape of the slip surface is linear. The underlying bedrock is $\mathrm{J}_{3 \mathrm{~s}}$ silty mudstone. Among them, the geological section $2-2^{\prime}$ of the main sliding direction of the landslide is shown in Figure 2.

Through carried out engineering geological surveying and drilled and other work, the following three types of strata were discovered from top to bottom in the site. Quaternary landslide accumulation layer $\left(\mathrm{Q}_{4}{ }^{\mathrm{del}}\right)$ : the thickness of the slip body is between $1.3 \mathrm{~m}$ and $15.6 \mathrm{~m}$; it is the main component of the landslide. It is dominated by silty mudstone, and the core is extremely broken. With the help of conventional rock and shear tests, it is found that the natural gravity of this layer of mudstone is $2.52 \mathrm{~g} / \mathrm{cm}^{3}$, the cohesion is $0.92 \mathrm{kPa}$, and the friction angle is $41.4^{\circ}$. Quaternary slope residual layer $\left(\mathrm{Q}_{4}{ }^{\mathrm{dl}+\mathrm{el}}\right)$ : this layer is dominated by purple-red clay particles, with a thickness between $1 \mathrm{~m}$ and $3 \mathrm{~m}$. Mesozoic Jurassic upper Suining formation $\left(\mathrm{J}_{3 \mathrm{~s}}\right)$ : the main component of this layer is silty mudstone, the internal structure is uneven, and there is a phenomenon of sandy concentration in some areas. At the same time, the joints and fissures of this layer are relatively developed, with a thickness of about $150 \mathrm{~m}$. Combined with the engineering geological survey data, it can be found that the formation of the landslide is directly affected by the fault fold belt of Longquan mountain. The general trend of the fault fold belt is NE $20 \sim 30^{\circ}$. According to the hydrological data of Taiping town for many years, the annual rainfall in this area is in the range of $800 \sim 1200 \mathrm{~mm}$. The construction of the landslide bid section started in May 2018. Affected by factors such as geology, hydrology, and preliminary excavation, the position of the slope toe was hollowed out. Then, the slope's shear strength was reduced, and conditions were created for rainwater infiltration. There is a tendency to slide along the weak slip surface. With the continuous infiltration of surface water, the slip body and slip surface soften. Therefore, the development of cracks accelerates, and the slip surface on the top of the bedrock gradually penetrates, thereby providing convenient conditions for the occurrence of landslide disasters. Heavy rainfall continued in Shuangliu area on June 8, 2018, with an average rainfall of $225 \mathrm{~mm}$ in August. At the end of August, the landslide began to show a small amount of local soil slip. At the beginning of September, many cracks appeared on the surface of the slope.

As shown in Figure 3, the anchor rod and frame anchor cable set in the front edge of the landslide have large deformation and even failure. During this period, the water content of the slip body is saturated. Under the influence of rain erosion and soil gravity and other factors, the original cracks in the slip body gradually disappeared, and the sliding soil is silted at the empty position at the foot of the slope. Figure 4 shows the deformation process of the landslide.

\section{Test Design}

3.1. Model Box Size and Rainfall Equipment. The size of the model box selected for this experiment is length $\times$ width $\times$ height $=3.0 \mathrm{~m} \times 0.6 \mathrm{~m} \times 1.0 \mathrm{~m}$. The model box is made of angle steel and $10 \mathrm{~mm}$ thick transparent tempered glass. As shown in Figure 5, the rainfall equipment is self-developed rainfall equipment, and the rainfall intensity is measured by a rain gauge.

3.2. Similar Relationship and Ratio of Similar Materials. The longitudinal length of the selected work point is $150 \mathrm{~m}$, and the length of the model box is $3.0 \mathrm{~m}$. Equation (1) is the calculation formula of the geometric similarity scale for this model test:

$$
C_{L}=\frac{L_{M}}{L_{P}}=50,
$$

where $C_{L}$ is geometric similarity constant; $L_{P}$ is prototype size, and $L_{M}$ is model size.

According to the determined geometrical similarity constant $\left(C_{L}=50\right)$, the similar parameters of the model design are shown in Table 1. 


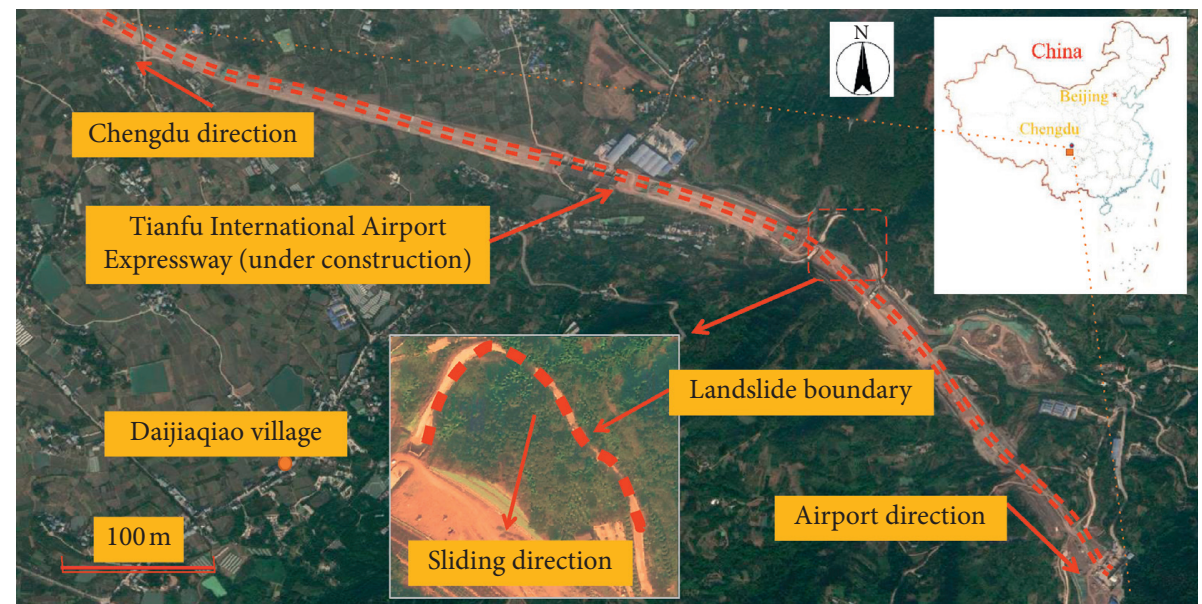

FIgURE 1: K17 + 700 K $17+900$ landslide view.

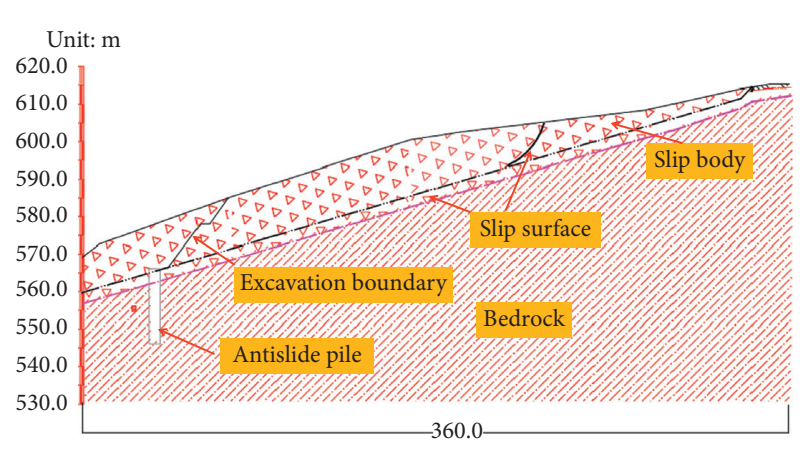

Quaternary landslide accumulation layer Suining formation of upper Jurassic in Mesozoic

Figure 2: No. 2-2' landslide engineering geological section (unit: m).

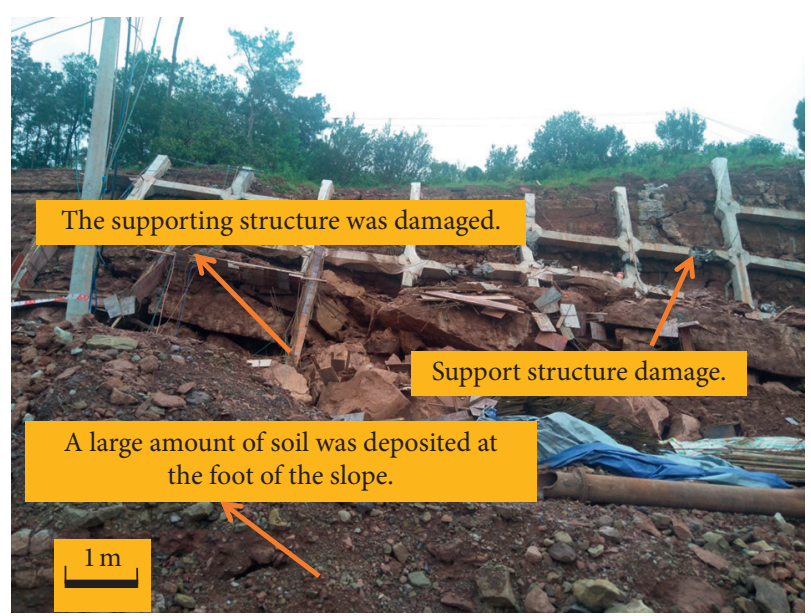

FIGURE 3: Failure diagram of frame anchor cable on landslide front edge.

3.3. Model Making. To simulate the sliding and deformation characteristics of bedding rock landslides, Yang et al. [26], Yang et al. [27], and Jia et al. [28] used gypsum, cement, sand, and gravel to fill the bedding landslide model in layers, which proved the feasibility of the filling method. Yin et al. [29] used Teflon material to simulate the weak interlayer. Li et al. [30], Ju et al. [31], and Tang et al. [32] used gypsum material to fill the soft bedding structure between the rock and soil and studied the failure mechanism and process of rock slopes. In view of this, this test model adopts the layered filling method. After each layer is filled, a layer of $1 \mathrm{~cm}$ thick gypsum was spread to simulate the bedding structure of the bedrock, and it is leveled and lightly pressed. As shown in Figure 6(a), in order to fully simulate the actual engineering situation and provide convenience for the sliding process of the slip body, a layer of impermeable Teflon film is laid between the slip body and the slip surface. Figure 6(b) is the completed test model. To facilitate the observation of experimental phenomena, a $2 \mathrm{~cm}$ wide vertical deformation observation zone was set up at the foot, middle, and top of the landslide.

The slip body of the selected site is dominated by block stones, and the permeability coefficient of the underlying mudstone is between $1 e^{-8} \mathrm{~cm} / \mathrm{s}$ and $1 e^{-7} \mathrm{~cm} / \mathrm{s}$, which is extremely low permeability and practically impermeable. During the simulated rainfall period, only a small part of the rainwater penetrated into the bedrock, which also showed that the rainwater has little effect on the bedrock part. The slip surface is dominated by silty mudstone, and its permeability coefficient is between $1.1 \times 10^{-8} \mathrm{~cm} / \mathrm{s}$ and $1.2 \times 10^{-8} \mathrm{~cm} / \mathrm{s}$. Li et al. [33] found that when the permeability coefficient of the weak interlayer is greater than or close to that of the slip body, no water accumulation or seepage occurs in the upper part of the interlayer. It can be seen that no obvious water accumulation or seepage occurs between the slip body, slip surface, and bedrock.

As shown in Figure 7, by carrying out the conventional direct shear test, the material parameters of the slip body, slip surface, and bedrock used in the test are determined as shown in Table 2.

3.4. Sensor Layout. According to the similarity ratio, the original slope model is simplified, and the simplified slope size and sensor layout are shown in Figure 8. The types of 


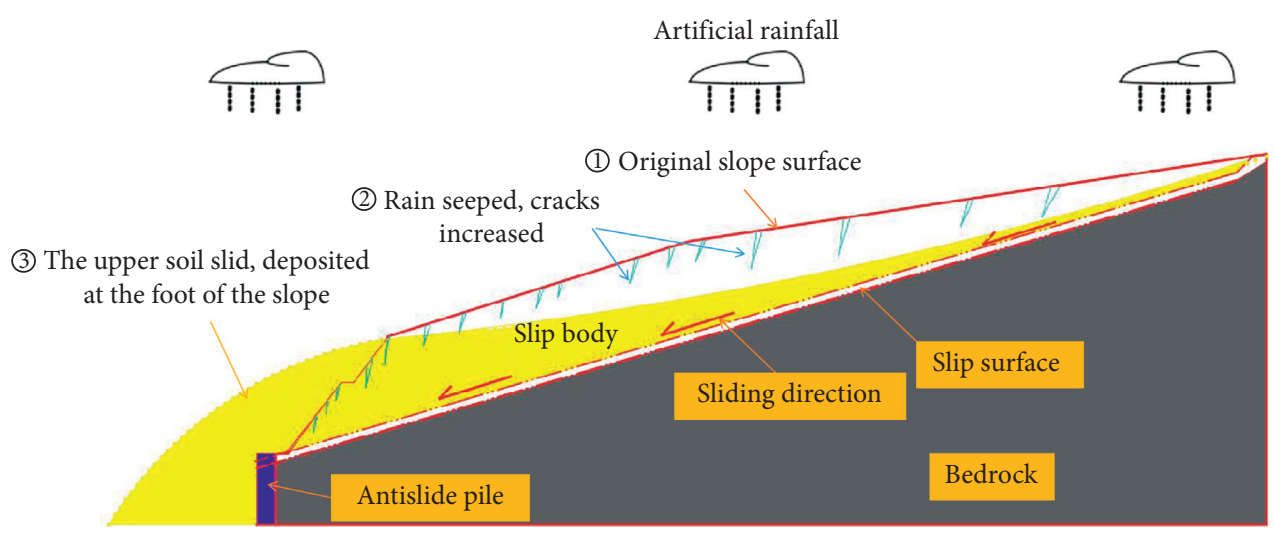

FIGURE 4: Schematic diagram of the landslide deformation process.

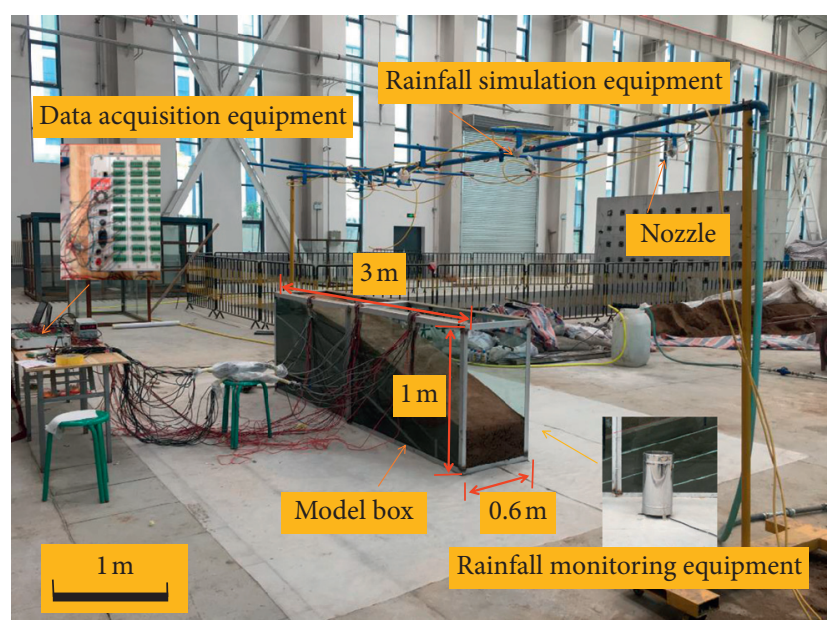

Figure 5: Rainfall equipment used in the test.

TABle 1: Model design similar parameters.

\begin{tabular}{lc}
\hline Physical quantity & Similar parameters \\
\hline Geometric size & $C_{L}=L_{M} / L_{P}=50$ \\
Bulk density & $C_{\gamma}=1$ \\
Friction angle & $C_{\varphi}=1$ \\
Cohesion & $C_{C}=C_{L} C_{\gamma}=50$ \\
\hline
\end{tabular}

sensors deployed include moisture content, strain, and stress sensors. In the slip surface and slip body, each measuring point is equipped with a moisture content, strain, and stress sensor, and the A measuring point is only equipped with moisture content and stress sensors. Three sets of sensors were set on the vertical section of the slope foot and the middle of the slope from top to bottom, and two sets are set on the vertical section of the top of the slope, and the vertical distance between them is $10 \mathrm{~mm}$.

3.5. Rainfall Condition Design. According to the data from the official website of the China Meteorological Administration [34], the distribution characteristics of annual average rainfall in Chengdu from 1990 to 2019 are shown in
Table 3. It can be seen from Table 3 that the maximum monthly rainfall in Chengdu occurred in August, with an average monthly rainfall of $245.8 \mathrm{~mm}$.

During the physical model test, not only the similarity principle of the geotechnical test model but also the rainfall similarity principle must be satisfied. The analysis of a large number of test cases showed that the Weber criterion can be regarded as the dominant criterion for landslide surface flow, whether laminar or turbulent. Liu et al. [35] assumed that the model and prototype had the same water density, surface tension, and other parameters; then Weber criterion was used to infer the relationship between the rainfall intensity scale and the model scale, as shown in the following equation:

$$
\lambda_{u}=\lambda_{l}^{-(1 / 2)}
$$

Since the scale of this model test is 50 , the rain intensity similarity scale can be calculated to be 0.14 . Combining the relationship between the rainfall data and the rainfall intensity similarity scale of the above-mentioned Chengdu area, when carrying out this physical model test, the rainfall working conditions are shown in Table 4. 


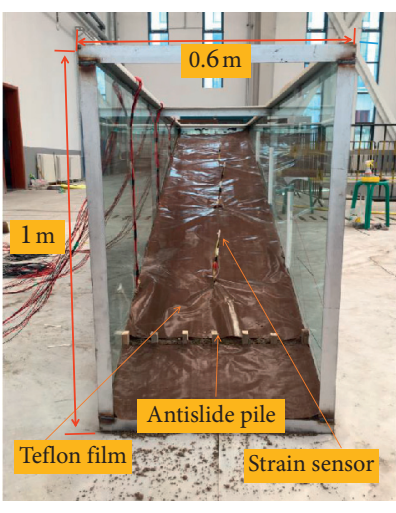

(a)

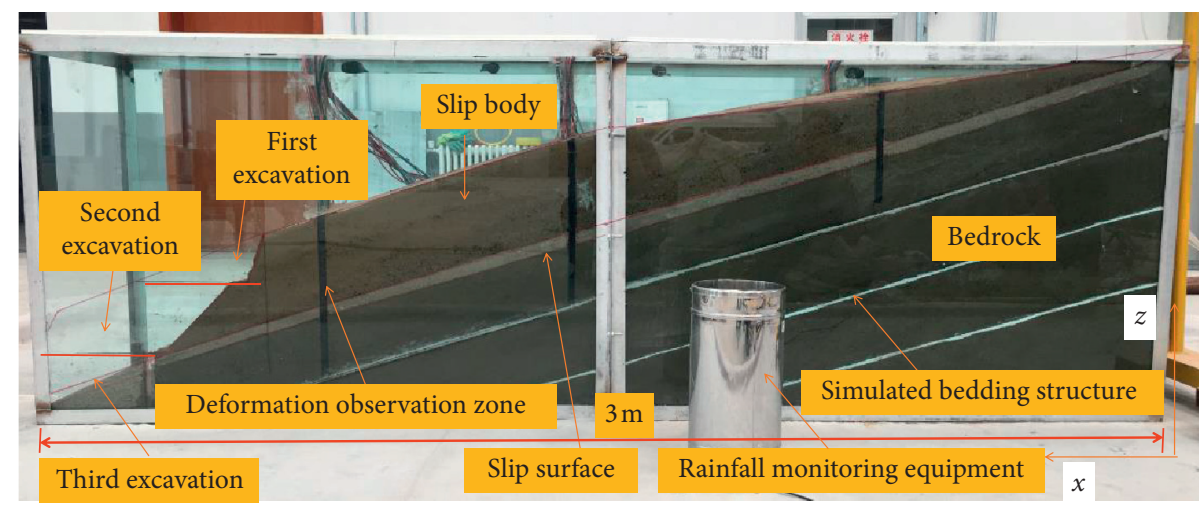

(b)

Figure 6: Test model filling. (a) Laying Teflon film. (b) Test model at the end of filling.

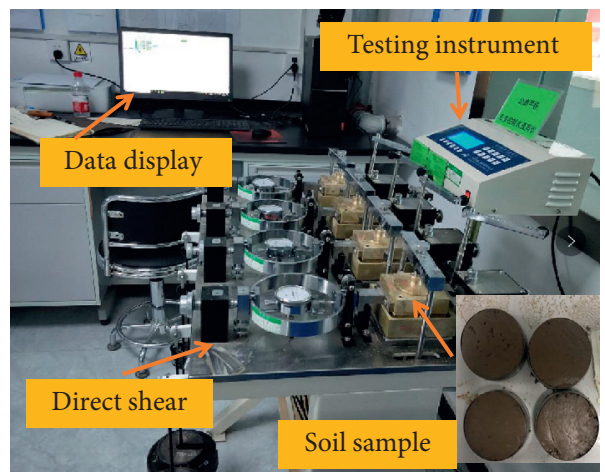

Figure 7: Conventional direct shear test.

TABLE 2: Similar material parameters.

\begin{tabular}{|c|c|c|c|c|}
\hline \multicolumn{2}{|c|}{ Material name } & Cohesion $(\mathrm{kPa})$ & Internal friction angle $\left({ }^{\circ}\right)$ & Similar material ratio \\
\hline Slip body & Model & 15.86 & 36.05 & Sand: soil: water $=0.5: 0.5: 0.1$ \\
\hline & Prototype & 8.2 & 34.3 & \\
\hline Slip surfac & Model & 0.85 & 29.88 & Sand: soil: talcum powder: water $=37: 52: 35: 15$ \\
\hline Bedrock & Prototype & 2.59 & 35.99 & Cement: sand: soil: water $=36: 18: 21: 8$ \\
\hline
\end{tabular}

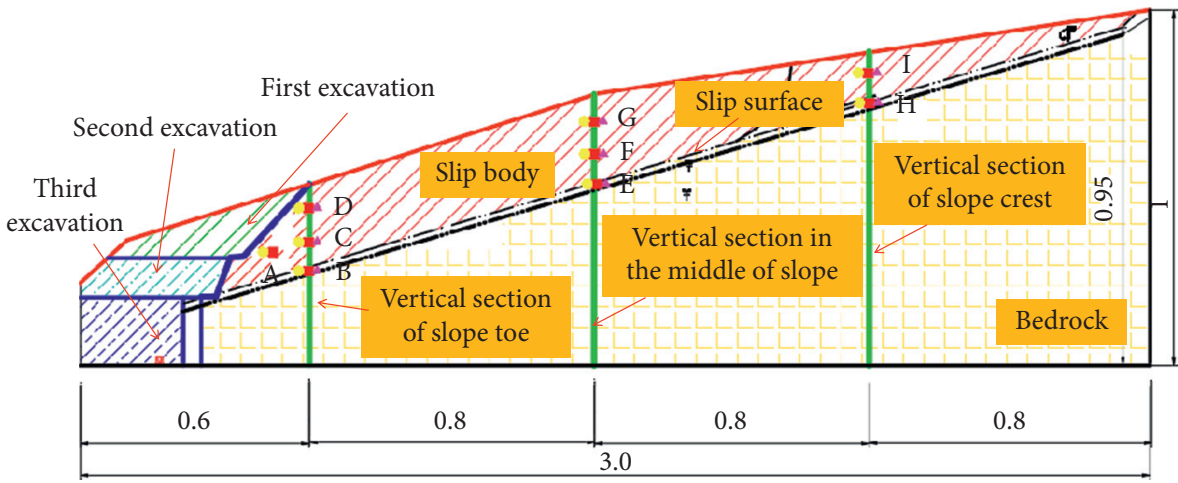

\footnotetext{
- Water content sener

- Stress sener

- Strain sener
}

FIGURE 8: Schematic diagram of sensor layout (unit: $\mathrm{m}$ ). 
TABle 3: Distribution characteristics of average rainfall in Chengdu from 1990 to 2019.

\begin{tabular}{lccc}
\hline Month & Max $(\mathrm{mm})$ & Min $(\mathrm{mm})$ & Average value $(\mathrm{mm})$ \\
\hline 1 & 22.9 & 2.0 & 8.5 \\
2 & 31.74 & 1.02 & 12.8 \\
3 & 37.6 & 10.2 & 24.0 \\
4 & 74.2 & 24.9 & 49.7 \\
5 & 111.8 & 20.6 & 69.1 \\
6 & 223.5 & 26.0 & 105.6 \\
7 & 330.2 & 90.2 & 205.3 \\
8 & 399.3 & 119.4 & 245.8 \\
9 & 218.7 & 32.0 & 108.8 \\
10 & 84.9 & 12.4 & 32.8 \\
11 & 37.1 & 6.4 & 14.5 \\
12 & 19.1 & 1.3 & 8.4 \\
\hline
\end{tabular}

TABLE 4: Rainfall condition design.

\begin{tabular}{lcc}
\hline Start and end time $(\mathrm{h})$ & Rainfall intensity $\left(\mathrm{mm} \cdot \mathrm{h}^{-1}\right)$ & Cumulative rainfall $(\mathrm{mm})$ \\
\hline $15: 00-16: 30$ & 30 & 30 \\
$16: 30-17: 30$ & 50 & 80 \\
$17: 30-18: 30$ & 40 & 120 \\
\hline
\end{tabular}

\section{Analysis of Test Results}

4.1. Test Phenomenon Analysis. Construction and static phase: to fully simulate the process of bedding rock landslides affected by rainfall and other factors during the construction and operation phases, slope excavation in three times (11: $00-11: 05,11: 30-11: 35,12: 00-12: 05)$. The excavation sequence and scope are shown in Figure 6. From 11:05 to 11: 30 , let stand 25 minutes. From $11: 35$ to $12: 00$, let stand 25 minutes. From 12:05 to 15:00, let stand 2 hours 55 minutes to simulate the construction process at the selected site.

Rainfall stage: the test started at 15:00 and ended at 18: 30. The test phenomena affected by the rainfall are summarized as follows: at $15: 45$, the soil at the foot of the slope near the sides of the left and right box walls collapsed and the soil fell siltation at the foot of the slope. At 15:45, Figure 9(a) shows that the part of the toe of the slope had multiple transverse cracks, and the rainwater on the right slope formed a runoff channel. At 16:10, affected by continuous rainfall, the existing cracks in the soil at the foot of the slope continued to develop, and the gully formed by the erosion of the water on the right slope at the corner of the slope continued to deepen. There were transverse and longitudinal cracks in the middle and back edge of the sliding mass. Figure 10(b) shows the cracks at the corresponding position of the back edge of the slope. As can be seen from Figure 9(b), the toe of the slope was seriously deformed and the cracks in the vertical section of the toe continue to widen and deepen. At 17:10, the existing cracks on the surface of the slope gradually disappeared owing to the sliding of the rear soil and the splash erosion of rain. Figure 9(c) shows that the soil sliding at the foot of the slope is further intensified. Figure 10(a) shows the damage phenomenon at the foot of the slope at the project site, the destruction phenomenon between the two is consistent. At 18:30, after the end of the test, in addition to the further aggravation of the slippage at the foot of the slope, by observing the change trend of the vertical observation zone on the side wall of the model box, it can be found that the deformation of the slope during the test is based on the soil deformation at the foot of the slope. Mainly, the soil deformation in the middle of the slope is the second. Figure 9(d) shows that the deformation of the soil at the top of the slope is the weakest.

The above part is the frontal test phenomenon of the model box, and the side test phenomenon of the model box is mainly reflected in the aspect of deformation. From 15: $00-17: 13$, the deformation of the landslide body is not obvious (Figures 11(a)-11(c)). After 17:13, the deformation gradually becomes faster (Figures $11(\mathrm{~d})$ and 11(e)). At the end of the test, at the upper part of the vertical section of the slope toe, the horizontal deformation reached $8 \mathrm{~cm}$ and the vertical settlement reached $6 \mathrm{~cm}$. In addition, by observing the test phenomenon on the side of the model box, it is found that the soil is mainly deposited on the top of the slope toe.

4.2. Deformation Analysis. The deformation of the foot of the slope is greater than the deformation of the slope, and the deformation of the slope is greater than the deformation of the top of the slope. It can be seen from the deformation of the position of the slope toe in Figure 11 that the upper part of the vertical section of the slope toe has obvious lateral displacement and vertical settlement. In the horizontal direction, the deformation value is $8 \mathrm{~cm}$, and the vertical settlement is $6 \mathrm{~cm}$.

Figure 12 shows the changes in the horizontal displacement of the vertical section of the toe during the entire test. It can be seen from Figure 12, the horizontal displacement at the bottom of the slope increases slowly at 15 : 00 to $17: 13$. From $17: 13$ to $18: 30$, the slope toe displacement increased significantly, and this period of time 


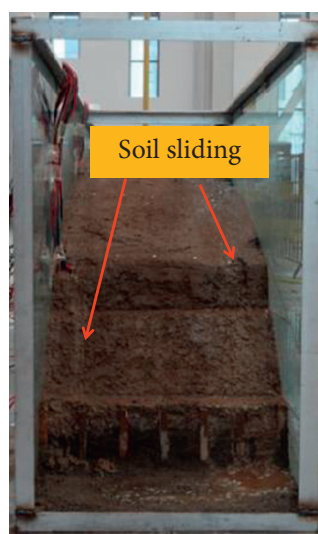

(a)

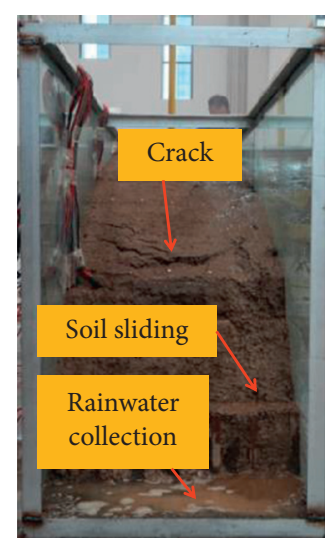

(b)

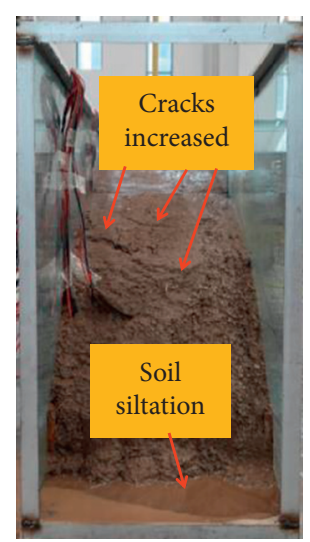

(c)

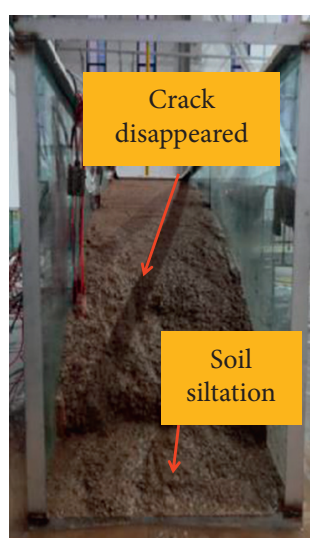

(d)

FIGURE 9: Summary of test phenomena. (a) $15: 45$. (b) $16: 10$. (c) $17: 10$. (d) $18: 30$.

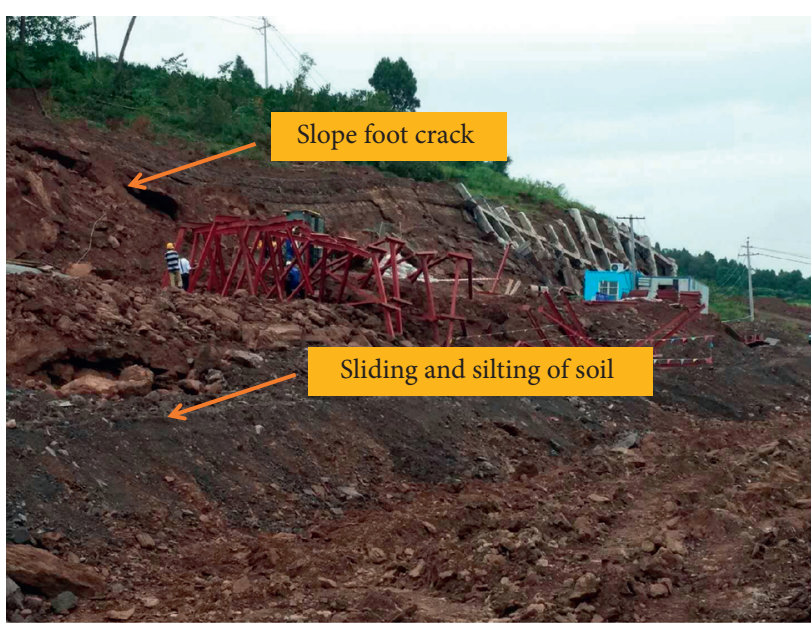

(a)

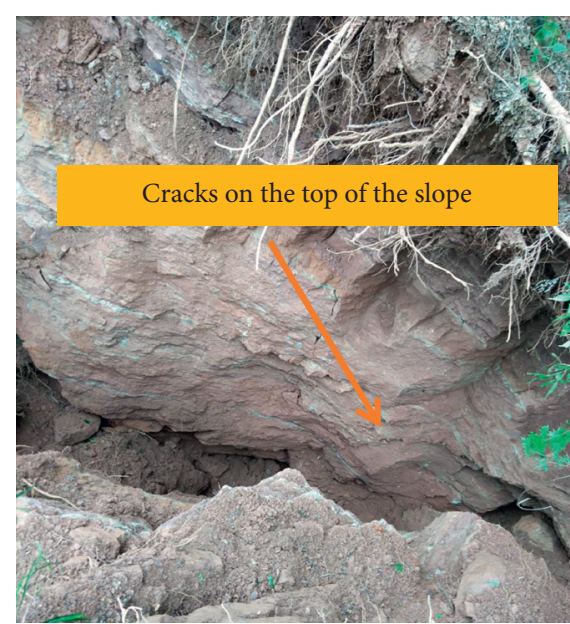

(b)

FIgURE 10: Engineering site pictures. (a) Slope foot. (b) Top of the slope.

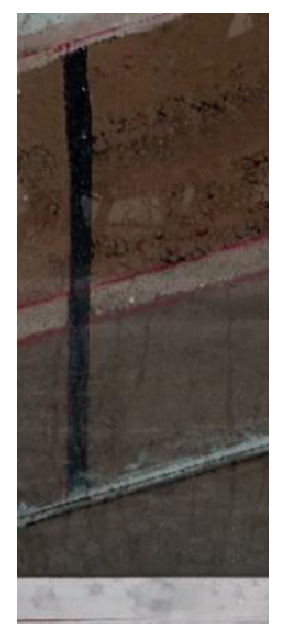

(a)

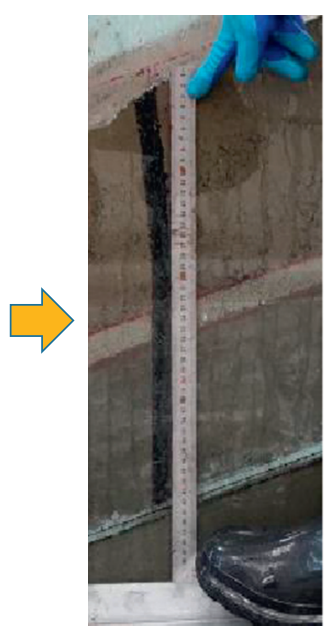

(b)

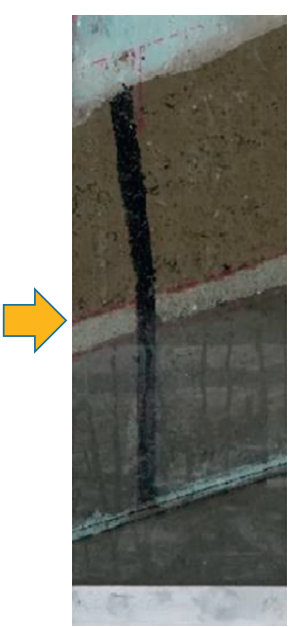

(c)

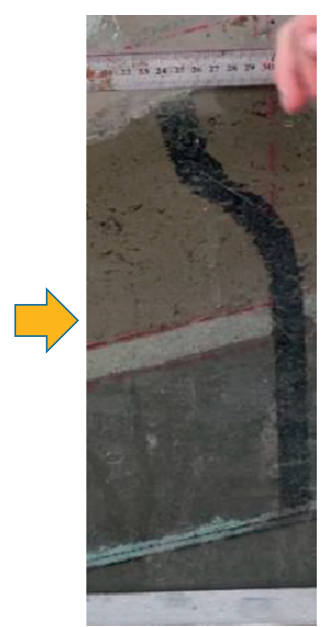

(d)

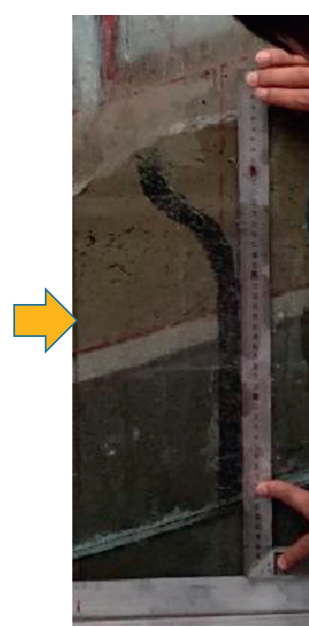

(e)

FIgURE 11: Horizontal displacement change of vertical section of slope toe. (a) $15: 41$. (b) $16: 18$. (c) $17: 13$. (d) $17: 54$. (e) $18: 30$. 

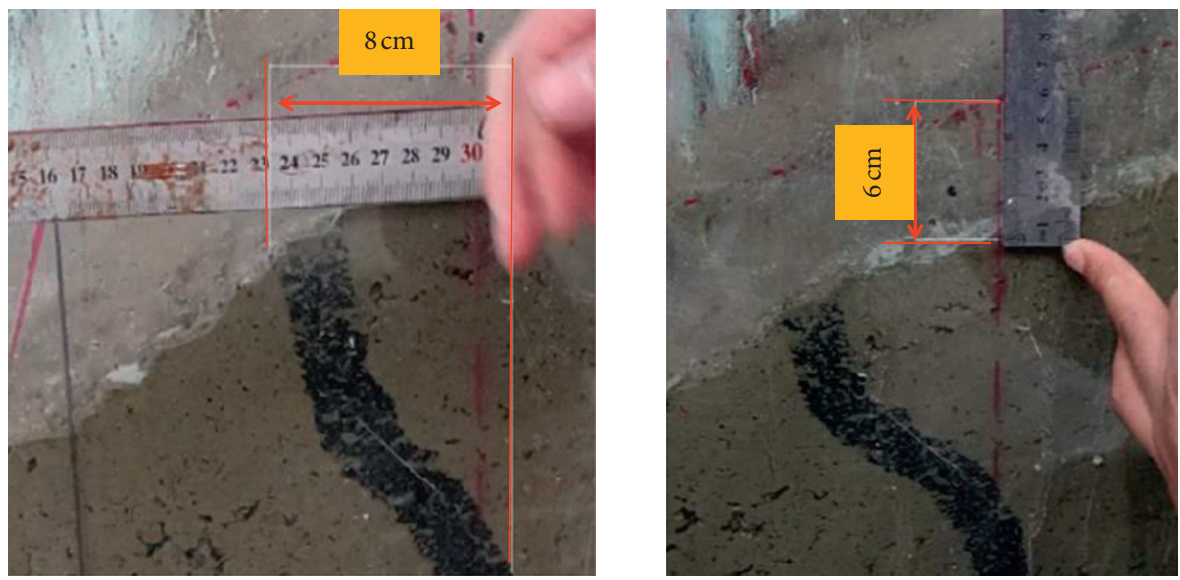

Figure 12: Displacement and settlement change of slope foot section.

corresponds to the accelerated deformation stage. Therefore, displacement can be used as an early warning indicator of landslide disasters under construction and rainfall conditions.

It can be seen from Figure 12, under the influence of construction excavation and rainfall, the deformation of the slope foot is the largest, and the deformation of the slope top is the smallest. The position of the slope foot is around 17: 00 , and there is obvious displacement. The horizontal displacement of the vertical section of the toe is greater than the vertical displacement, and the vertical section deformation of the slope toe is mainly concentrated in the accelerated deformation stage. Therefore, displacement change can be used as an indicator of landslide disaster warning.

\subsection{Strain Analysis}

4.3.1. Vertical Section of Toe. To understand the coupling response of the slip body and the sliding belt strain-water content during the whole test period, draw the strain-water content time history curve of the vertical sections B and D of the slope foot (Figure 13).

Construction stage: during the entire construction period from 11:00 to $12: 05$, the strain at the $B$ and $D$ measuring points at the vertical section of the slope toe showed a slow increase trend. Under the influence of construction disturbance factors, the sliding force inside the slip body and slip surface is slightly greater than the antisliding force, and the landslide body is in the initial deformation stage.

Static stage: from 12:06 to $15: 00$, the sliding force and antisliding force at measuring points $\mathrm{D}$ and $\mathrm{B}$ are basically maintained in a dynamic equilibrium state. At this time, the strain growth rate remained basically unchanged, but the sliding force was slightly greater than the antisliding force. At this stage, the strain values of the two measuring points B and D increased slightly. Since the measuring point B is located directly below the measuring point $\mathrm{D}$, it is strongly restrained by the surrounding soil mass and the strain value is relatively small. The strain at measuring point $\mathrm{D}$ is always greater than that of $\mathrm{B}$, and the landslide body is in the stage of constant velocity deformation.

Rainfall stage: after 15:01, the rainfall system is turned on, the water content of measuring point $\mathrm{D}$ has a sharp increase before point $\mathrm{B}$. With the continuous infiltration of rainwater, the measuring point $\mathrm{D}$ is gradually in a relaxed state, the stress around the measuring point gradually dissipates, the stress in the upper area of the slope toe section gradually approaches 0 . Affected by this, although the strain value of measuring point $\mathrm{D}$ has a slight increase, it is basically maintained at a small value. The measurement point $B$ is located inside the slip surface. With the continuous infiltration of rainwater, the soil moisture content reaches a saturated state at about $16: 30$. The bulk density of the soil around point $\mathrm{B}$ increases, and the stress continues to increase, coupled with the impact of the surrounding soil. Then, the stress cannot be dissipated, causing the strain value of the $\mathrm{B}$ measuring point to increase sharply. Slope toe section changes from the initial acceleration deformation stage to the middle acceleration deformation stage. Affected by continuous rainfall, rainwater that cannot infiltrate in time forms a runoff phenomenon on the surface and takes away small particles in the soil, which increases the deformation around the measuring point. At the same time, the continuous infiltration of rainwater reduces the stress of the vertical section at the angle of the slope, and the strain values of measuring points B and D gradually decrease. At this time, the toe of the slope is in the acceleration deformation stage, and the vertical section of the toe collapses and loses stability.

4.3.2. Sliding Body D, I Plane. Measurement point $\mathrm{D}$ is located at the upper part of the vertical section of the slope toe, and measurement point I is located at the upper position of the vertical section of the top of the slope. From the strainwater content time history curve of measurement points $\mathrm{D}$ and I in Figure 14, the strain of the entire slip body increases to a certain extent in the initial and constant deformation stages. The sliding force is greater than the antisliding force, 


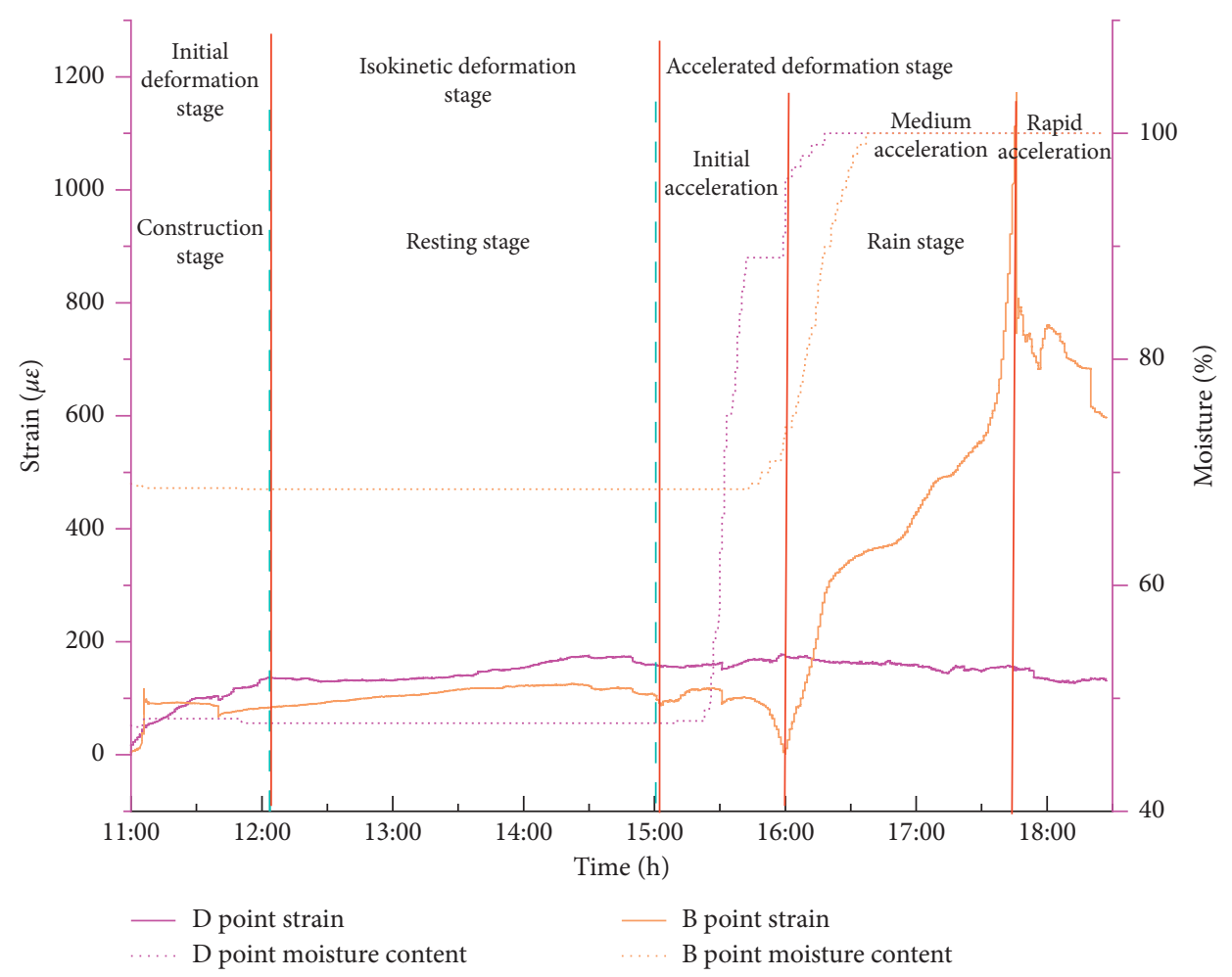

Figure 13: B, D measuring points strain-water content time history curve.

and the deformation process continues. Throughout the construction and operation phase, the strain value of the $\mathrm{D}$ measuring point is always greater than the I measuring point.

The above research shows, the strain change of each measuring point is generally divided into three stages, initial, constant velocity, and accelerated deformation. In the initial and constant deformation stage, the strain value of each measuring point has a slight increase (within $200 \mu \varepsilon$ ). Entering the accelerated deformation stage, the strain values of vertical sections $B$ and $D$ of slope toe first increase and then decrease. Point $B$ is located in the slip surface, the increase in strain value is much larger than that of measuring point $D$ affected by the impact of the surrounding soil. During the period of $15: 30-16: 30$, the strain value has changed significantly, and strain can be used as an indicator of landslide warning.

4.4. Stress Analysis in Soil. To understand the coupling of soil pressure-water content at the foot of the slope under rainfall conditions, draw the stress-water content time history curve of the vertical section at the foot, middle, and top of the slope.

Construction stage: Figure 15 shows the stress-water content time history curve of the vertical sections $\mathrm{C}$ and $\mathrm{D}$ of the slope toe. It can be seen from Figure 16 that, as the progressive excavation work $(11: 11-11: 05,11: 30-11: 35$, $12: 00-12: 05)$ is carried out in an orderly manner, the stress at each measuring point of the vertical section of the slope foot has a small stepped increase, and the stress remains positive. The slip body changes from the original free state to

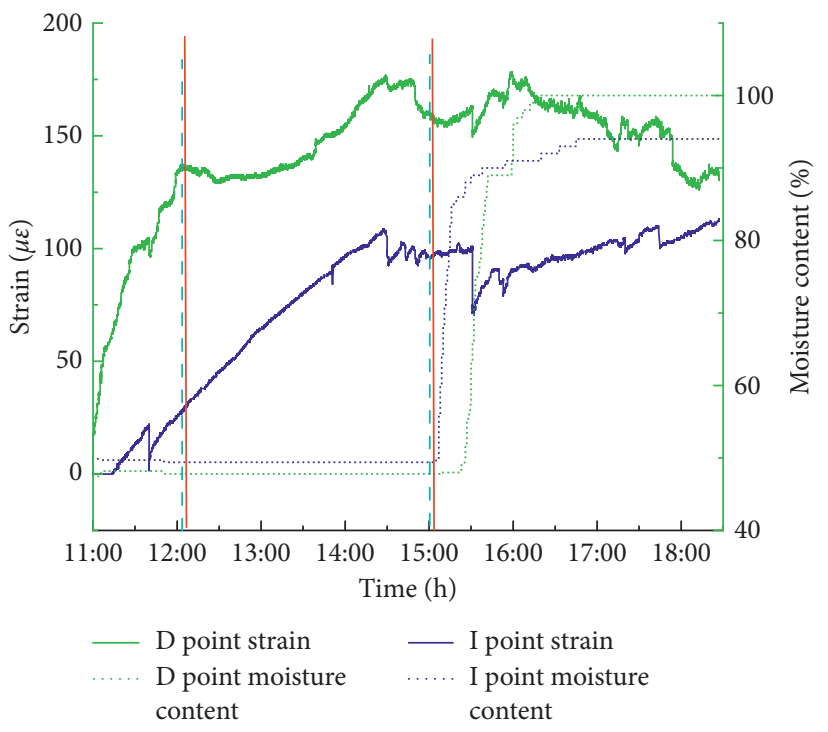

FIGURE 14: D, I measuring points strain-water content time history curve.

the compressed state; the original equilibrium state is broken. The deformation starts suddenly, and the soil behind the slope has a small pushing effect on the soil at the foot and in the slope. At this time, the sliding force at the foot of the slope is greater than the antisliding force. With the end of the excavation work (12:05), the sliding force of the rear soil is basically the same as the antiskid force. The stress growth rate is basically maintained at a constant state, the internal stress of the soil is redistributed, and the slope is in the initial deformation stage. 


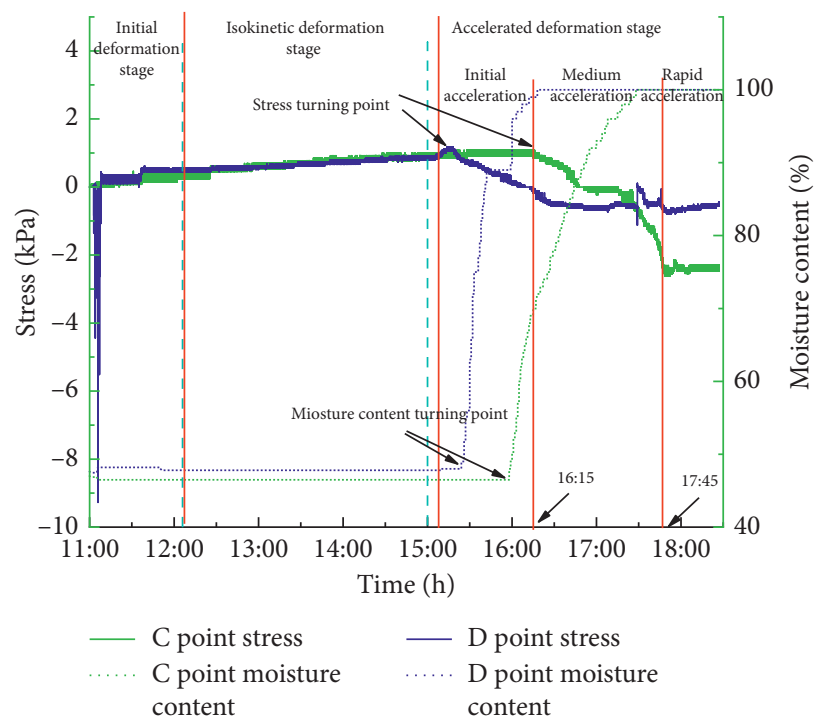

FIGURE 15: Stress-moisture content time history curve at C and D measuring points of the vertical section of slope foot.

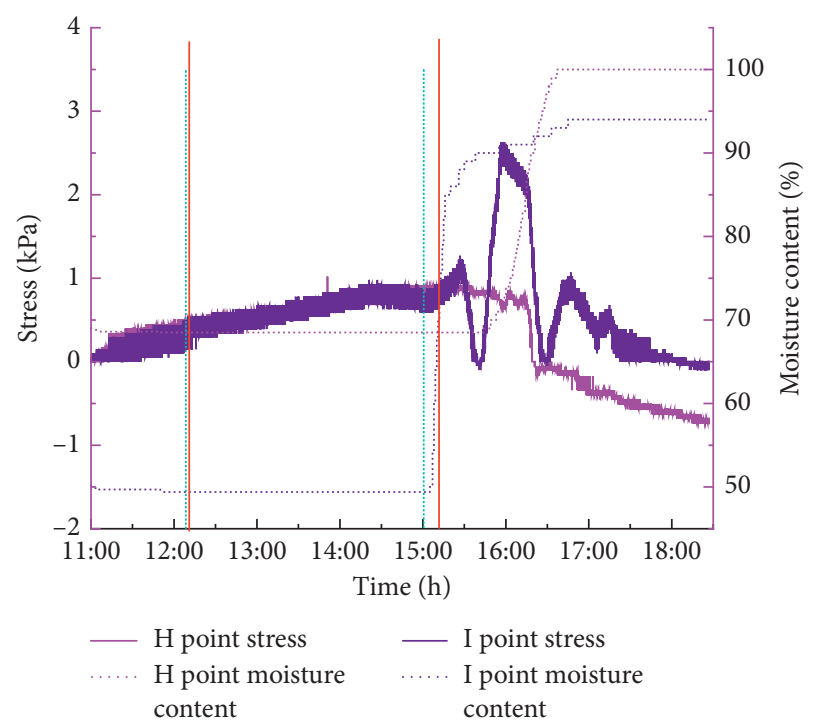

FIGURE 16: Time history curve of stress-moisture content at $\mathrm{H}$ and I measuring points of the vertical section of slope top.

Static phase: during $12: 30$ to $15: 00$, the influence of external factors, such as construction excavation and rainfall, weakened, and "microfracture" [36] inside the soil continued to proceed. The front of the slope toe is in a state of being in the air, the stress of each measuring point increases slowly after the addition of the squeezing action of the earth mass. The soil pressure growth rate of the vertical section of the slope toe remains constant, and the stresswater content time history curve basically remains straight. At this time, the landslide is in the stage of constant velocity deformation.

Rainfall stage: the rain system started at 15:00 in this test. The $\mathrm{D}$ measuring point is located directly above the $\mathrm{C}$ measuring point, the arrival time of the water content turning point at the $\mathrm{D}$ measuring point is obviously about 10 minutes earlier than the $\mathrm{C}$ measuring point. At this moment, under the influence of rainwater seepage, the soil moisture content and bulk density increase, so the stress of the D measuring point increases slightly. However, as the water content of measuring point $\mathrm{D}$ increases sharply in a short period of time, the soil mass around the measuring point infiltrates and fractures intensified. The shear stress and horizontal stress continue to decrease, and the stress value gradually decreases to a negative value. By $16: 15$, the initial acceleration phase of the slip body is over. During the period from $16: 15$ to $17: 45$, the water content at point $D$ remains unchanged, and although the stress fluctuates slightly, the value remains basically unchanged. With the continuous increase of the water content of the measuring point $C$, the surrounding soil infiltration is more obvious, and the stress 


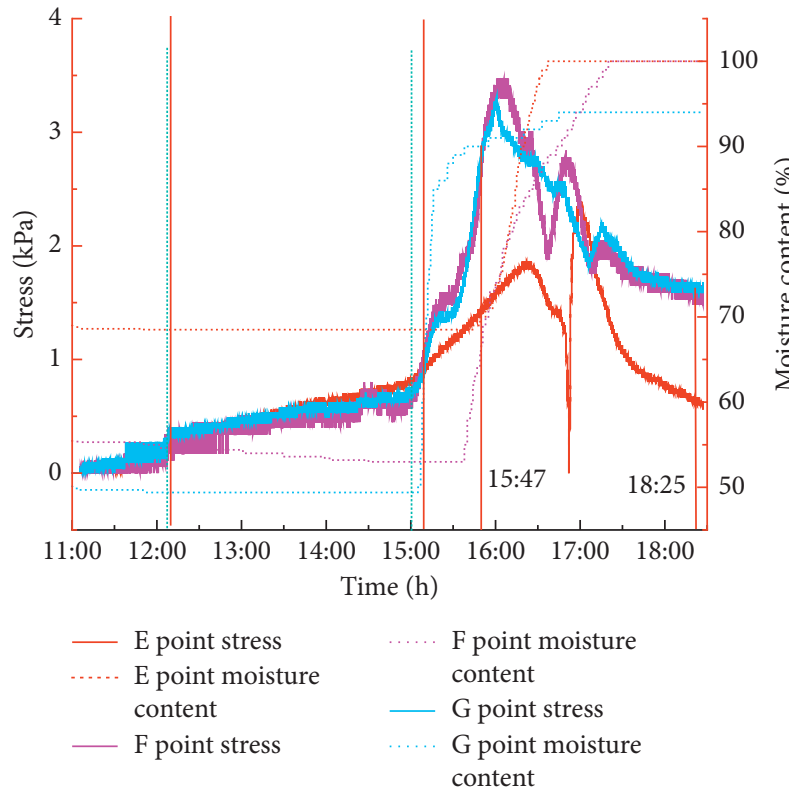

(a)

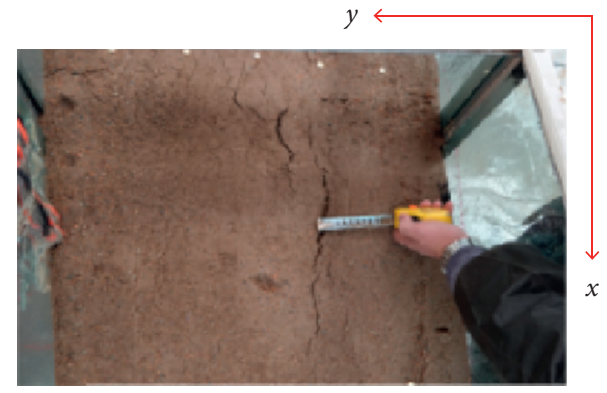

(b)

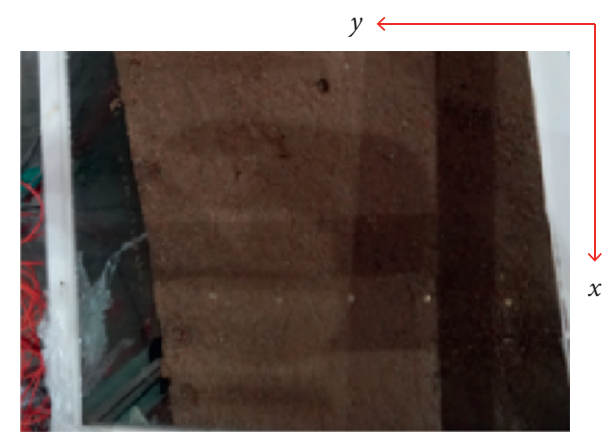

(c)

FIGURE 17: Stress-moisture content time history curve of vertical sections E, F, G in slope.

is less than 0 , indicating that the traction in front of the measuring point $\mathrm{C}$ is dominant. The cracks in the slope toe section gradually healed, and the stress also changed from positive to negative. Under this influence, the sliding process in the middle and rear positions of the slip body starts, and the landslide body is in the middle acceleration stage. After $17: 50$, the stresses at measuring points $C$ and $D$ remain basically unchanged, but since the elevation of point $\mathrm{D}$ is greater than that of point $C$, the stress value of point $C$ is obviously greater than that of measuring point $D$. The landslide body is in the acceleration and deformation stage, and the toe section of the slope has collapse and instability (Figure 9(d)). At the later stage of the acceleration deformation stage, the slip body enters a state of presliding, and the slip surface is completely penetrated. The viscous force between the soil mass disappears quickly, and the slip body changes from a creeping state to a sudden slipping state. The original cracks on the surface of the slope gradually disappeared under the influence of sliding silt and rainwater splash erosion, and the entire slope was instability and damaged.
The stress-water content time history curves of the vertical sections E, F, G in the slope are shown in Figure 17. The stress change trend of vertical sections E, F, G in the slope is basically the same as that of C and D, so I will not repeat it.

Rainfall stage, after the rainfall system, is started at 15 : 00 , the $\mathrm{G}$ and $\mathrm{F}$ measuring points located on the upper part of the vertical section of the slope are affected by rainwater seepage before the E measuring point. The water content and stress turning points of $\mathrm{G}$ and $\mathrm{F}$ measuring points appeared earlier than point $\mathrm{E}$, and they increased rapidly. The stress at point $\mathrm{F}$ increased from $0.84 \mathrm{kPa}$ before rainfall to $3.49 \mathrm{kPa}$, the stress at point $\mathrm{G}$ increased from $0.79 \mathrm{kPa}$ before rainfall to $3.24 \mathrm{kPa}$, the stress at measuring point $\mathrm{E}$ increased from $0.68 \mathrm{kPa}$ before rain to $2.37 \mathrm{kPa}$, indicating that the sliding force of the vertical section in the slope is far greater than the antisliding force. At this point, Figure 17(b) shows that horizontal cracks appear in the vertical part of the slope. The soil on the slope interruption surface is not only blocked by the front soil but also affected by the displacement of the rear soil, and the landslide has entered the accelerated 


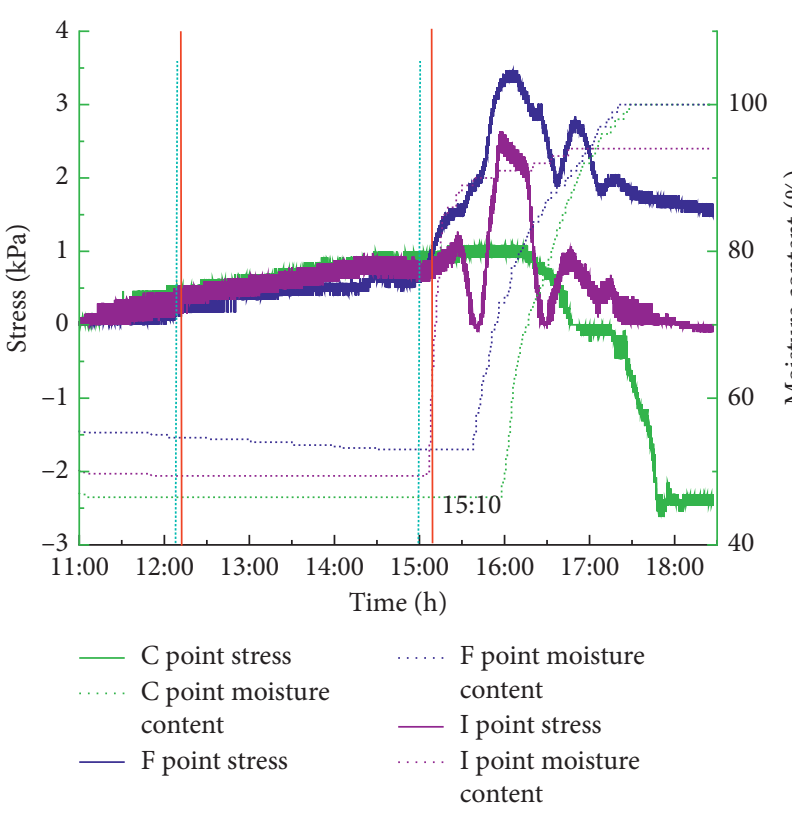

(a)

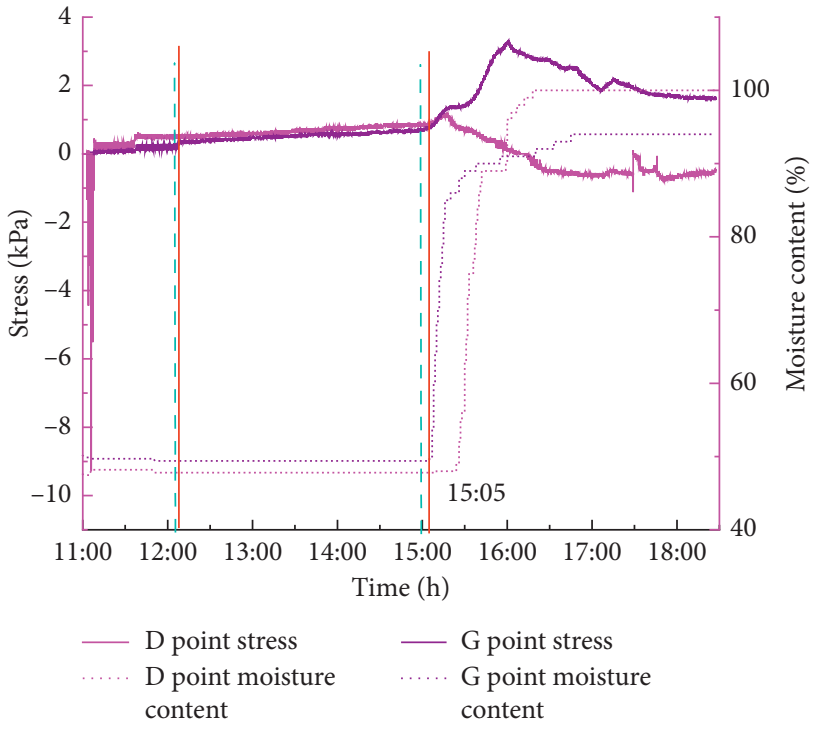

(b)

FIGURE 18: Time history curve of stress-water content in the upper and lower planes of the sliding body. (a) C, F, I measuring point. (b) D, G measuring point.

deformation stage. After 16:00, as the water content of each measuring point approaches saturation. Although the stress of the three measuring points has a certain range of oscillations, the overall performance is a downward trend. Compared with the slope toe section, the soil in the middle of the slope is always under pressure due to the obstruction of the front soil. The stress at each side point of the central section of the slope is always maintained at a positive value, indicating that the squeezing force at the central position of the slope is greater than the traction. With the continuous rainfall process, the infiltration intensified. Figure 17(c) shows that the cracks in the middle of the slope gradually disappear. After 18:00, the earth pressure gradually stabilized, and the slip surface inside the slope was completely connected.

Figure 16 shows the stress-water content time history curve of the vertical sections $\mathrm{H}$ and I of the top of the slope. The changes in earth pressure during the construction and static phases are basically the same as the vertical section of the toe and the middle of the slope. After starting the rainfall system at 15:00, the stress value in the soil under the influence of water content increases rapidly, and the pushing effect in the soil is greater than the traction effect.

Figure $18(\mathrm{a})$ is the stress-water content time history curve at C, F, I measurement points, and Figure 18(b) is the stress-water content time history curve at D and G measurement points. It can be seen from Figure 18 that the stress-water content time history curves in the initial and constant deformation stages are basically the same, and the stress values have a slight increase. After the rainfall system was started at 15:00, the earth pressure increased around $15: 05$ at the D and G measuring points. However, the C, F, and I measurement points are affected by the embedding depth, and the stress increases at around 15:10. With the continuous progress of rainfall, after 17:00, although the stress values of $\mathrm{C}$ and $\mathrm{D}$ measuring points oscillated slightly, they remained below 0 . It shows that the toe section of the slope is greatly affected by the traction of the front soil, the stress at the measuring points $G$ and $F$ of the slope interruption surface, and the measuring point I of the slope crest section is maintained above 0 . The front soil body has local collapse and slipping deformation, showing a traction sliding mode [37].

The above study shows the bedding rock landslide can be divided into three different stages: initial, constant velocity, and accelerated deformation. Under the combined action of rainfall, construction disturbance, and other factors, the sliding mode of bedding rock landslides is a composite sliding mode with both sliding and traction sliding. During the period of 15:05-16:00, the stress value of each measuring point in the soil has changed obviously.

\section{Conclusion}

By carrying out the physical model test, analyzing data such as earth pressure, strain, displacement, and moisture content measured in the test, and studying the deformation mechanism and catastrophic evolution process of bedding rock landslides under the influence of rainfall and construction factors, the conclusions are as follows.

As the water content of the slip body and slip surface increases, the stress, strain, and displacement all change significantly. Under the influence of rainfall, construction disturbance, stratum structure, and other factors, the earth pressure, strain, and displacement values at different positions in the landslide body have all undergone significant 
changes. In addition, the law of various parameters changing with time is basically the same.

Under the influence of rainfall and other comprehensive factors, the bedding rock landslide has experienced three different stages of initial, constant velocity, and accelerated deformation from start to finish. The sliding mode of bedding rock landslides is a composite sliding mode with both sliding and traction sliding.

During the deformation and failure of the landslide, the sensitivity of displacement, strain, and stress indicators is different. In addition, the stress response is the fastest, the strain response is the second, and the displacement response is the slowest.

In the initial, constant velocity deformation stage, the stress and strain values measured in the test have a slight increase. Entering the accelerated deformation stage, the horizontal and vertical displacement of the top position of the vertical section of the slope foot increased rapidly, and the strain value increased significantly. The earth pressure at the foot of the slope is greatly reduced, and the earth pressure in the middle of the slope is greatly increased; stress, strain, and displacement can be used as early warning indicators for bedding rock landslide disasters under rainfall conditions.

Combined with the stress, strain, displacement, and other data measured by the model test, it can be seen that, under the influence of rainfall and other factors, the weak sliding surface in the landslide body gradually penetrates, and the stress in the slip surface decreases [38, 39]. Furthermore, it provides conditions for slope sliding.

Affected by rainfall, excavation of the slope toe, and other factors, the position of the toe of the landslide body is deformed most obviously. The soil of the slope toe has a traction effect on the sliding of the slope and triggers the sliding of the soil in the middle and top of the slope. The deformation starts at the foot of the slope.

\section{Data Availability}

The data used to support the findings of this study are available from the corresponding author upon request.

\section{Conflicts of Interest}

The authors have no conflicts of interest to declare.

\section{Authors' Contributions}

Zhi-Yang Ji and Hong-Gang Wu contributed equally to this work and should be considered co-first authors. Tian-Wen Lai performed the technological development. Zhi-Yang Ji and Hong-gang $\mathrm{Wu}$ prepared and edited the manuscript.

\section{Acknowledgments}

The authors gratefully acknowledge the financial support by the National Key R\&D Program of China (no. 2018YFC1504903) and Natural Science Foundation of Gansu Province (no. 145RJZA068).

\section{References}

[1] E. V. Kalinin, L. L. Panas, and E. M. Timofeev, "A new approach to analysis of landslide slope stability," Moscow University Geology Bulletin, vol. 63, no. 1, pp. 19-27, 2008.

[2] C. D. Ventisette, G. Gigli, M. Bonini et al., "Insights from analogue modelling into the deformation mechanism of the vaiont landslide," Geomorphology, vol. 228, pp. 52-59, 2015.

[3] P. Lollino, G. Elia, F. Cotecchia, and G. Mitaritonna, "Analysis of landslide reactivation mechanisms in daunia clay slope by means of limit equilibrium and FEM methods," in Proceedings of the 2010 Geotechnical Special Publication, pp. 3155-3164, Orlando, FL, USA, February 2010.

[4] T. Toshiya, C. Yoji, and U. Tadakazu, "Estimation of the rotational-movement type landslide deformation process based on comparison between inclination rate and displacement rate-inclination," Japanese Geotechnical Journal, vol. 8, no. 1, pp. 23-33, 2013.

[5] Q. Xu, M. G. Tang, K. X. Xu, and X. B. Huang, "Research on space-time evolution laws and early warning-prediction of landslides," Chinese Journal of Rock Mechanics and Engineering, vol. 27, no. 6, pp. 1104-1112, 2008.

[6] M. J. Crozier, "Prediction of rainfall-triggered landslides: a test of the antecedent water status model," Earth Surface Processes \& Landforms, vol. 24, no. 9, pp. 825-833, 2015.

[7] A. Rahimi, H. Rahardjo, and E.-C. Leong, "Effect of hydraulic properties of soil on rainfall-induced slope failure," Engineering Geology, vol. 114, no. 3-4, pp. 135-143, 2010.

[8] W. T. Oh and S. K. Vanapalli, "Influence of rain infiltration on the stability of compacted soil slopes," Computers and Geotechnics, vol. 37, no. 5, pp. 649-657, 2010.

[9] S. Luciani, M. Brunetti, and S. Peruccacci, "Rainfall thresholds for the initiation of landslides in central italy using remote sensing precipitation data," in Proceedings of the 2011 Agu Fall Meeting, San Francisco, CA, USA, December 2011.

[10] G. Martelloni, S. Segoni, and R. Fanti, "Rainfall thresholds for the forecasting of landslide occurrence at regional scale," Landslides, vol. 9, no. 4, 2012.

[11] M. Xia, G. M. Ren, and X. L. Yang, "Mechanism of a catastrophic landslide occurred on May 12, 2019, Qinghai Province, China," Landslides, vol. 18, pp. 707-720, 2020.

[12] P. Ma and H. Zhang, "Instability mechanism and reflection of low-gentle bedding slope of Wengma expressway," Journal of Catastrophology, vol. 34, no. S1, pp. 154-156, 2019.

[13] M. Mao, X. Y. Zhou, Z. P. Zhou, Z. J. Fan, Z. B. Xiang, and M. Liu, "Study on deformation destruction of gently inclined bedding rock slope and the treatment technology," Subgrade Engineering, vol. 6, pp. 40-45, 2015.

[14] J. Wasowski, "Understanding rainfall-landslide relationships in man-modified environments: a case-history from caramanico terme Italy," Environmental Geology, vol. 35, no. 2-3, pp. 197-209, 2008.

[15] R. Chowdhury and P. Flentje, "Uncertainties in rainfall-induced landslide hazard," Quarterly Journal of Engineering Geology and Hydrogeology, vol. 35, no. 1, pp. 61-69, 2002.

[16] A. Sengupta, S. Gupta, and K. Anbarasu, "Rainfall thresholds for the initiation of landslide at Lanta Khola in north Sikkim, India," Natural Hazards, vol. 52, no. 1, pp. 31-42, 2010.

[17] M. Berti, M. L. V. Martina, S. Franceschini, S. Pignone, A. Simoni, and M. Pizziolo, "Probabilistic rainfall thresholds for landslide occurrence using a bayesian approach," Journal of Geophysical Research Earth Surface, vol. 117, no. F4, 2012.

[18] M. Melillo, M. T. Brunetti, S. Peruccacci, S. L. Gariano, and F. Guzzetti, "Rainfall thresholds for the possible landslide 
occurrence in Sicily (Southern italy) based on the automatic reconstruction of rainfall events," Landslides, vol. 13, no. 1, pp. 165-172, 2016.

[19] F. W. Y. Ko and F. L. C. Lo, "Rainfall-based landslide susceptibility analysis for natural terrain in Hong Kong," Engineering Geology, vol. 215, pp. 95-107, 2016.

[20] M. Floris and F. Bozzano, "Evaluation of landslide reactivation: a modified rainfall threshold model based on historical records of rainfall and landslides," Geomorphology, vol. 94, no. 1-2, pp. 40-57, 2008.

[21] C. Vennari, S. L. Gariano, L. Antronico et al., "Rainfall thresholds for shallow landslide occurrence in calabria, southern Italy," Natural Hazards and Earth System Sciences, vol. 14, no. 2, pp. 317-330, 2014.

[22] H. J. Park, J. H. Lee, and I. Woo, "Assessment of rainfallinduced shallow landslide susceptibility using a gis-based probabilistic approach," Engineering Geology, vol. 161, pp. 115, 2013.

[23] G. Crosta, "Regionalization of rainfall thresholds: an aid to landslide hazard evaluation," Environmental Geology, vol. 35, no. 2-3, pp. 131-145, 1998.

[24] N. L. J. Dolojan, S. Moriguchi, M. Hashimoto, and K. Terada, "Mapping method of rainfall-induced landslide hazards by infiltration and slope stability analysis," Landslides, vol. 20, pp. 1-19, 2021.

[25] SCHDRI, Chengdu Tianfu International Airport Expressway K17+700 K17+900 Landslide Engineering Geological Survey Report, SCHDRI, Chengdu, China, 2011.

[26] G. L. Yang, Q. Shen, Y. L. Yi, and M. M. Qiu, "Numerical analysis and shaking table test of acceleration response of combined supporting structure on bedding slope," Journal of Sun Yat-Sen University, vol. 56, no. 1, pp. 28-35, 2017.

[27] J. W. Yang, Y. Chen, L. Zhang, B. Q. Yang, and M. R. Li, "Study on the stability of bedding high rock slope based on the comprehensive method of geomechanical model test," Chinese Journal of Rock Mechanics and Engineering, vol. 37, no. 1, pp. 131-140, 2018.

[28] X. N. Jia, Q. B. Huang, T. Wang, N. Zhang, and Z. K. Jiang, "Shaking table test study on dynamic response of loessmudstone slope in steeply inclined bedding fracture zone," Chinese Journal of Rock Mechanics and Engineering, vol. 37, no. 12, pp. 2721-2732, 2018.

[29] X. T. Yin, Z. Y. Feng, F. Yan, D. Y. Wang, and Y. Q. Qin, "Safety assessment of bedding slope on Huaping bank of Jinsha River Bridge on Huali Expressway based on static model test," Chinese Journal of Rock Mechanics and Engineering, vol. 36, no. 5, pp. 1215-1226, 2017.

[30] L. Q. Li, S. X. Luo, W. K. Wei, C. Y. Wang, H. Xu, and J. Xu, "Model test study on the influence of rainfall infiltration on the behavior of bedding rock slope with weak interlayer," Chinese Journal of Rock Mechanics and Engineering, vol. 9, pp. 1772-1778, 2013.

[31] N. P. Ju, T. X. Deng, L. Q. Li, J. Y. Jiang, and C. Y. Zhang, "Centrifugal shaking table test on the toppling deformation mechanism of steep bedding slopes under strong earthquakes," Rock and Soil Mechanics, vol. 40, no. 1, pp. 99-108, 2019.

[32] H. M. Tang, H. K. Chen, and W. W. Cao, "Model test of excavation process of bedding rock slope," Rock and Soil Mechanics, vol. 19, no. 2, pp. 435-444, 2011.

[33] H. R. Li, P. Zhang, S. N. Wang, and H. P. Zhao, "Study on the influence of slope stability of downtrend coal measures under rainfall conditions," Journal of Geomechanics, vol. 24, no. 6, pp. 871-878, 2018.
[34] China meteorological administration. [DB/OL]. http://www. cma.gov.cn, 2020..

[35] D. R. Liu, W. Q. Zhang, X. Z. Huang, and C. C. Li, "Research on indoor model test of water and heat variation process of unsaturated loess slope," Rock and Soil Mechanics, vol. 38, no. S2, pp. 236-240, 2017.

[36] S. R. Zhang, Y. S. Tan, C. Wang, and M. Yu, "Influence of the characteristics of heavy rainfall on the instability and failure of saturated-unsaturated slopes," Chinese Journal of Rock Mechanics and Engineering, vol. 33, no. 2, pp. 4102-4111, 2014.

[37] Q. Xu, M. G. Tang, and R. Q. Huang, Large-scale Landslide Monitoring and Early Warning and Emergency Response, Science Press, Beijing, China, 2015.

[38] Z. G. Tao, C. Zhu, M. C. He, and M. Karakus, "A physical modeling-based study on the control mechanisms of negative poisson's ratio anchor cable on the stratified toppling deformation of anti-inclined slopes," International Journal of Rock Mechanics and Mining Sciences, vol. 138, 2021.

[39] B. Li, R. Bao, Y. Wang, R. Liu, and C. Zhao, "Permeability evolution of two-dimensional fracture networks during shear under constant normal stiffness boundary conditions," Rock Mechanics and Rock Engineering, vol. 54, no. 3, pp. 1-20, 2021. 